
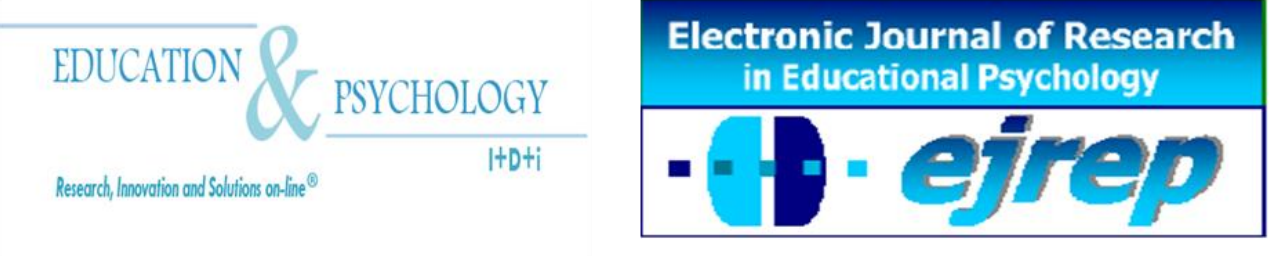

Editorial EOS

\title{
Validity and Reliability of an Attention Deficit and Hyperactivity Disorder Measure for a Sample of Omani Children
}

\author{
Ibrahim A. Alqaryouti ${ }^{1}$, Maher M. Abu Hilal ${ }^{2}$ \\ And Mahmoud M. Ibrahim ${ }^{3}$
}

\footnotetext{
${ }^{1}$ Early Childhood Education, Sultan Qaboos University, Muscat

2 Department of Psychology, Sultan Qaboos University, Muscat

${ }^{3}$ Department of Psychology, Sultan Qaboos University, Muscat
}

\section{Sultanate of Oman}

Correspondence: Ibrahim AlQaryouti, P.O. Box 32, Sultan Qaboos University, Al Khodh, PC 123. Oman. Email: $\underline{\text { ibrahimq@squ.edu.om }}$

(C) Education \& Psychology I+D+i and Editorial EOS (Spain) 


\begin{abstract}
Introduction. The purpose of this study was to develop and validate a diagnostic measure of attention deficit, hyperactivity disorder and impulsivity.

Method. The instrument was administered to normal ( $n=51)$, learning disability (LD) (n=96), and intellectually disabled (ID) $(n=108)$ children. The instrument in its final form comprises 36 items.

Results. Reliability analysis, exploratory factor analysis, and confirmatory factor analysis revealed that the instrument possesses good reliability and validity estimates. MANOVA revealed that intellectually disabled, learning disabled and normal children differed significantly on all of the five subscales. The pattern of difference mainly favored I.D. children then L.D. The lowest scores on all of the subscales were those of the normal children.

Discussion and Conclusion. It is important that children with L.D. be differentiated from other types of disabilities. The instrument at hand is presumed to make such distinction. Namely, the instrument is a tool to identify children with attention deficit and hyperactivity disorder.
\end{abstract}

Keywords: ADHD, learning difficulty, intellectual disability, construct validity

Received: 02/27/11 Initial acceptance: 03/16/11 Final acceptance: 07/ 


\section{Validez y fiabilidad de una medida del trastorno de déficit de atención con hiperactividad en una muestra de alumnos omaníes}

\section{Resumen}

Introducción. El propósito de este estudio fue desarrollar y validar una medida de diagnóstico de déficit de atención, hiperactividad e impulsividad.

Método. El instrumento fue aplicado a un muestra normal $(\mathrm{n}=51)$, con problemas de aprendizaje $(\mathrm{LD})(\mathrm{n}=96)$ y con discapacidad intelectual $(\mathrm{DI})(\mathrm{n}=108)$ niños. El instrumento en su forma final consta de 36 artículos.

Resultados. El análisis de fiabilidad, análisis factorial exploratorio y el análisis factorial confirmatorio revelaron que el instrumento posee una buena fiabilidad y validez de las constructo. El MANOVA reveló que con discapacidad intelectual, el aprendizaje de los niños discapacitados y normales difirieron significativamente en todas y cada una de las cinco subescalas. El patrón de la diferencia favorecido principalmente a los niños ID y LD. Las puntuaciones más bajas en todas las subescalas fueron las de los niños normales.

Discusión y Conclusión. Es importante que los niños con LD se diferencian de otros tipos de discapacidades. El instrumento en cuestión pretende hacer tal distinción. Es decir, el instrumento es una herramienta para identificar a los niños con déficit de atención e hiperactividad.

Palabras clave: TDAH, dificultades de aprendizaje, discapacidad intelectual, la validez de constructo.

Recibido: 09/11/10 Aceptación inicial: 16/02/11 Aceptación final: 24/04/11 


\section{Introduction}

Attention is one of the basic mental processes and it plays a crucial role in the lives of individuals and in their abilities to interact and communicate with surrounding environment. It has been established that attention influences learning, achievement as well as interaction among individuals (Alzayat, 1998; Hallahan, Lloyed, Kauffman, Weiss \& Martinez, 2005). Attention's impact is clearly observed among school children who suffer from attention deficit. Those children suffer from difficulty in concentrating on a specific stimulus among the many stimuli that they encounter. Also, they have difficulty in arranging their cognitive activities and focusing on one stimulus for a reasonably long time and may attend to secondary stimuli that may distract their attention. This may be accompanied by behavior problems such as hyperactivity and impulsiveness.

Attention deficit and hyperactivity disorder (ADHD) is one of the common problems among children and adolescents. The ratio of the problem ranges between $3 \%-5 \%$, and it varies from one country to another depending on the sample selection procedure and the tool used to identify those who are categorized as having ADHD (Alhamed, 2002; Alzayat, 1998; Jou, Handen \& Harden, 2004; Salehi, Noah \& Jaafar, 2011; Sisalem, 2001). Intellectually disabled children can have attention deficit, learning difficulty, and weak understanding, perception and memory. These problems may get aggravated as disability becomes severe pronounced. Also, intellectually disabled children suffer from distraction, weak concentration for a long time, and difficulty in identifying the stimuli that are related to the required tasks (Alkhatib \& Alhadidi, 2004; Alrusan, 2006; Yahia \& Obied, 2005) and weak problem solving skills (Sheban, Mohamed \& Jaafar, 2011).

Arab researchers seem to agree with Western researchers on the characteristics of the ID. For example, Hallahan and Kauffman (2003) indicated that ID children have weak attention, hyperactivity, inability to complete the work on time, and interruption of others. Those who suffer weak attention and hyperactivity, have difficulty in classifying, organizing, and synthesizing things as well as an inability to have social relationships with peers. ID children can't follow instructions, game rules, or role exchange. The percentage of children with ADHD among intellectually disabled children ranges between 9\% and 18\% (Jou et al., 2004). 
Learning disability is one of the invisible and non-consistent disability; whether, in terms of its characteristics or symptoms. This may complicate things for those who diagnose this disability and those who provide educational programs for individuals with LD. Learning disability appears in the developmental and academic domains. The first is related to problems of perception as well as psychomotor coordination and cognition. The second (academic domain) is related to problems of reading, writing, arithmetic and composition (Aldhaher, 2004; Alkawafha, 2005; Alshahat \& Ashoor, 2003; Alqabali, 2003; Jarrar, 2008; Lerner, 2003; Mercer, 1997; Salem, Smith \& Corkum, 2007).

Researchers have indicated that several reasons are behind the overlap between ADHD and LD. Learning disability is conceived to precede attention deficit so that some behaviors may reflect attention deficit because of frustration that children incur due to repeated failures. It is also possible that attention deficit may precede learning difficulty. This may lead to failure in learning which may be detrimental to achievement. LD and ADHD may appear separately or simultaneously (Hallahan et al., 2005). About $20 \%$ to $25 \%$ of children with LD have ADHD; and 75\% of those with ADHD have learning difficulty (Failgel, 1998).

The standard definition and criteria for diagnosis of ADHD were devised by the American Psychiatric Association in the Diagnostic and Statistical Mental Disorder (DSM). The latest edition of the manual was the fourth (American Psychiatry Association, 2000) which contained diagnostic standards for ADHD. The standards were three and subsumed 18 characteristics. Any individual who may be diagnosed as an ADHD should exhibit 6 of the characteristics of the attention deficit and at least 6 characteristics of the hyperactivity and impulsiveness. Barkly (1998) indicated that children who suffer ADHD may exhibit developmental characteristics in early age that do not match their chronicle age and may affect their attention and activity. Alwaqfi (2003) defined hyperactivity as the behavior that is abnormally actively constant. A person with this kind of behavior moves from one activity to another with no goal to achieve. Also, for a behavior to be classified as disorder, four criteria should be met:

1) Symptoms should be more frequent and variable than among normal children.

2) Symptoms should appear earlier than age of seven.

3) Symptoms should appear no less than six months.

4) Symptoms should not be attributed to mental, physical or emotional disorder. 
Dills (2001) summarized the symptoms of the ADHD in one definition. He stated that ADHD is a set of traits that show weak attention, excessive activity that would happen frequently in more than one social condition. The DMS IV-TR (2000) mentions the following diagnostic criteria for the ADHD:

First, item 1 or item 2 -listed below- should apply to the child to be diagnosed as an ADHD.

Item (1), a child should show six or more of the following behavioral symptoms that indicate attention deficit for a period of no less than six months. The behavioral problems are:

1- Failure to attend to details or to commit silly mistakes during performing homework or any other task.

2- Difficulty in maintaining attention during task performance.

3- Difficulty to listen during conversation.

4- Failure to follow instructions.

5- Difficulty in organizing tasks and activities required of him/her.

6- Avoiding homework that requires mental effort.

7- Loss of things, tools, and materials.

8- Easily distracted.

9- Forgetting daily activities.

Item (2), Six of the symptoms of hyperactivity and impulsiveness should characterize the child and should appear for no less than six months. These symptoms are:

1- Body movement to express anxiety and boredom.

2- Departing the seat when should be seated.

3- Unjustifiable running and climbing furniture.

4- Difficulty in playing or engaging in leisure activities quietly.

5- Hyperactivity.

6- Excessive talking.

7- Impulsive answers even before hearing the question.

8- Difficulty to say in a queue.

9- Interruption of others and interfering in discussion without permission (American Psychiatric Association, 2000). 
Karande, Satam, Kalkarni, Sholapurwala, Chitre \& Shah (2007) studied 50 individuals who were identified as having learning difficulty, attention deficit and hyperactivity. They found that $96 \%$ of the sample had difficulty in writing, $96 \%$ had difficulty in attention, $96 \%$ had problems in mathematics, 68\% hyperactivity disorder and $60 \%$ had reading difficulty. Lahey, Pelham, Chronis, Massetti, Kipp, Ehardt \& Lee (2006) investigated the reliability of predictive criteria of the ICD-10. In the process, hyper kinetic disorder was related to attention deficit hyperactivity disorder. The results revealed that all 95 children who met the standards of ICD-10 also met the standards of DSM-IV. However, only $26 \%$ of those identified as ADHD patients and who met the standards of DSM-IV, met the standards of ICD-10.

Researcher across the world have relied on DSM-IV or ICD-10 to develop local checklists or rating scales. Most of those researchers (Adler et al., 2006; Alsayed, 1999; Conner, 1997; Eiraldi, Power \& Karustis, 2000; Simonsen \& Bullis, 2007) have found that their instruments were valid and reliable. Therefore, our reliance on the DSM-IV is expected to produce a valid and reliable instrument for the Omani environment.

Probably, no other concept in the field of special education has been critiqued and reviewed as the concept of attention deficit hyperactivity impulsiveness disorder (ADHD). One of the main reasons behind such revision and critique has been that this disorder prevails among normal, learning disabled and intellectually disabled children. ADHD has negative consequences on learners and on the planning of programs for those learners. It is important to note that planning of remedial programs relies on valid diagnosis. Without valid diagnosis, the work of specialists, and the efficacy of the programs may remain doubtful. The literature in Arabic revealed that research is scarce in this particularly area. Very few studies have studied attention deficit- hyperactivity and impulsiveness (Alsayed, 1999; Jreisat, 2007).

The field experience of the researchers revealed that diagnosis rely heavily on school marks in mathematics and reading, but no other valid and reliable diagnostic tools are available to the special education specialists. The purpose of this study was to provide the field of education, in general, and special education, in particular, with a valid and reliable instrument for diagnosis of ADHD in the Sultanate of Oman. It is expected that such a valid instrument would help teachers, special education specialists as well as parents in the diagnosis of this subtle disorder. Moreover, we are interested in examining whether our instrument is valid 
across the three groups (i.e., normal, LD and ID). Certainly, the results would have strong implications as to whether diagnosis of LD and ID students is accurate or not.

\section{Method}

\section{Participants}

The sample of this study consisted of normal students $(n=51)$, learning disabled (LD) students $(n=91)$ from grammar public schools in the city of Muscat, Sultanate of Oman; and intellectual disability (ID) children $(n=108)$ from a private school of intellectual disability in the city of Muscat. Normal students were selected randomly from the schools that have learning disabled students where our student teachers were trained. Because this group of students is only recently attended to, only few schools have learning disabled children.

\section{Instrument}

Based on the literature, the authors developed a multidimensional diagnostic scale to represent the three main domains included in DSM-IV and ICD-10: attention deficit, hyperactivity and impulsiveness. The instrument was built around the following five subscales:

1) Attention and memory deficit (AMD): This scale is part of the attention deficit domain. The scale encompasses 9 items $(1,2,4,5,6,7,9,12$, and 35 in Appendex $)$ that measure attention and memory problems. Examples of the items: 'forgets information that he/she learns', 'can't follow instructions.'

2) Organization and responsibility (OR): this scale is the second part of the attention deficit domain. It encompasses 9 items $(3,8,10,11,13,14,15,16$, and 36 in Appendex) that measure problems in organization and responsibility. Examples of the items are: 'can be responsible for tasks assigned to him/her' (reversed), 'keeps and protects books and other school things' (reversed). Although the two subscales belong to the attention deficit, this scale has more psycho-social weight while AMD has more developmental weight.

3) Non-purposive movement (NPM): this scale is part of the hyperactivity domain. It comprises 7 items $(17,18,19,22,23,26$, and 27 in Appendex) purported to measure excessive 
and no-purposive movement. Examples of the items are: 'keeps standing and sitting in class', 'runs into class furniture when he/she moves.'

4) Cooperation with others $(\mathrm{CO})$ : This scale is the second part of the hyperactivity domain. It comprises 5 items $(20,21,24,25$, and 28 in Appendex) that assess how the child is cooperative and conforming. Examples of the items are: 'cooperative with teachers and supervisors,'(reversed) 'apologizes if he/she misbehaves' (reversed). This subscale has psychosocial component whereas the NPM has a developmental component of the hyperactivity.

5) Impulsiveness (IM): this is a standalone scale that measures impulsiveness. It comprises 6 items (29, 30, 31, 32, 33 and 34 in Appendex). Examples of the items are: 'all his/her requests should be responded to promptly,' 'runs and jumps hastily without thinking about consequences.'

After drafting the items (42 items), the items were given to 9 referees at the college of education at SQU. The referees were asked to indicate if the items belonged to the subscale under which they were listed. No serious alterations were suggested and therefore no changes were made to the instrument until the items were analyzed. The instrument was filled out by the teacher who knew the student for at least one full semester. The teacher was required to indicate if the statement or symptom (item) 'never happens,' 'sometimes happens,' 'usually happens' or 'always happens'. These alternatives were scored 1, 2, 3, and 4, respectively.

Table 1 shows scale names, number of items, and alpha Chronbach estimates for each scale after some weak items were deleted. Alphas ranged between .78 and .91. Alphas were large and suitable for research and diagnostic purposes.

Table 1. Subscale names, number of items and alpha Cronbach.

\begin{tabular}{rccc}
\hline No. & Scale & No of items & alpha \\
\hline 1 & Attention and Memory deficit (AMD) & 9 & .88 \\
2 & Organization and Responsibility (OR) & 9 & .91 \\
3 & Non Purposive Movement (NPM) & 7 & .90 \\
4 & Cooperation with Others (CO) & 5 & .86 \\
5 & Impulsiveness (IM) & 6 & .78 \\
\hline
\end{tabular}




\section{Procedure}

After all necessary permits were secured, the researchers met with teachers and explained the instrument and the way in which it should be filled. The researchers emphasized transparency, objectivity and honesty in filling out the instrument. The teachers were then given about 2 weeks from the beginning of the spring semester of 2008 to return the filled instruments. Teachers (raters) were encouraged to contact the researchers whenever they needed to inquire about any item in the instrument.

\section{Statistical Analysis}

To test the validity and reliability of the Omani Scale of Attention DeficitHyperactivity and Impulsiveness (OSADHI) instrument, several statistical procedures were used. Confirmatory factor analysis (CFA) with maximum-likelihood method, and reliability analyses with alpha Cronbach were used and are reported here. MANOVA was also used to compare groups of students on the subscales. Reliability analysis was based on single items. However, to obtain higher reliability of subscales and based on the recommendation of methodologists (e.g., Abu-Hilal \& Bahri, 2000; Marsh, Byrne, \& Shavelson, 1988) in measurement, parceling of items was performed. The parceling process was performed by summing item scores to make a parcel (indicador). Therefore 16 indicator were used in the CFA.

\section{Results}

\section{Descriptive statistic}

Table 2 shows the means, standard deviation and correlation coefficients for the parcels. The parcels were fairly normal and the correlations among parcels were all significantly positive. 
Table 2. Zero-Order Correlation Coefficients, Means and Standard Deviations among the Parcels of the Instrument

\begin{tabular}{|c|c|c|c|c|c|c|c|c|c|c|c|c|c|c|c|c|}
\hline & Ad1 & $\operatorname{Ad} 2$ & Ad3 & Ad4 & Ad5 & Ad6 & $\operatorname{Im} 1$ & $\operatorname{Im} 2$ & $\operatorname{Im} 3$ & Hy1 & Hy2 & Hy3 & Hy4 & Hy5 & Hy6 & Hy7 \\
\hline Ad1 & 1 & & & & & & & & & & & & & & & \\
\hline $\operatorname{Ad} 2$ & $.792^{* *}$ & 1 & & & & & & & & & & & & & & \\
\hline Ad3 & $.623^{* *}$ & $.651^{* * *}$ & 1 & & & & & & & & & & & & & \\
\hline $\mathrm{Ad} 4$ & $.423^{* *}$ & $.426^{* *}$ & $.415^{* *}$ & 1 & & & & & & & & & & & & \\
\hline Ad5 & $.443^{* *}$ & $.484^{* *}$ & $.428^{* * *}$ & $.747^{* *}$ & 1 & & & & & & & & & & & \\
\hline Ad6 & $.479^{* *}$ & $.502^{* *}$ & $.448^{* * *}$ & $.809^{* *}$ & $.755^{* *}$ & 1 & & & & & & & & & & \\
\hline $\operatorname{Im} 1$ & $.330^{* *}$ & $.326^{* *}$ & $.173^{* *}$ & .036 & $.141^{*}$ & .115 & 1 & & & & & & & & & \\
\hline $\operatorname{Im} 2$ & $.362^{* *}$ & $.302^{* *}$ & $.222^{* *}$ & $.145^{*}$ & $.146^{*}$ & $.206^{* *}$ & $.543^{* *}$ & 1 & & & & & & & & \\
\hline $\operatorname{Im} 3$ & $.338^{* * *}$ & $.273^{* *}$ & $.232^{* * *}$ & $.199^{* *}$ & $.177^{* *}$ & $.217^{* *}$ & $.356^{* * *}$ & $.583^{* *}$ & 1 & & & & & & & \\
\hline Hy1 & $.292^{* *}$ & $.242^{* *}$ & $.256^{* *}$ & $.252^{* *}$ & $.311^{* *}$ & $.258^{* * *}$ & $.394^{* * *}$ & $.580^{* *}$ & $.616^{* *}$ & 1 & & & & & & \\
\hline Hy2 & $.391^{* *}$ & $.318^{* *}$ & $.293^{* * *}$ & $.321^{* *}$ & $.334^{* *}$ & $.333^{* *}$ & $.396^{* * *}$ & $.628^{* *}$ & $.613^{* *}$ & $.725^{* *}$ & 1 & & & & & \\
\hline Нy3 & $.347^{* *}$ & $.308^{* *}$ & $.267^{* *}$ & $.168^{* *}$ & $.203^{* *}$ & $.160^{*}$ & $.322^{* * *}$ & $.544^{* *}$ & $.666^{* *}$ & $.689^{* *}$ & $.615^{* *}$ & 1 & & & & \\
\hline hy4 & $.327^{* *}$ & $.279^{* *}$ & $.216^{* *}$ & $.240^{* * *}$ & $.220^{* *}$ & $.215^{* *}$ & $.403^{* * *}$ & $.622^{* *}$ & $.693^{* *}$ & $.716^{* *}$ & $.675^{* *}$ & $.718^{* *}$ & 1 & & & \\
\hline Hy5 & $.368^{* *}$ & $.349^{* *}$ & $.277^{* *}$ & $.708^{* *}$ & $.652^{* *}$ & $.726^{* * *}$ & $.182^{* * *}$ & $.240^{* *}$ & $.300^{* *}$ & $.376^{* *}$ & $.402^{* *}$ & $.300^{* * *}$ & $.355^{* *}$ & 1 & & \\
\hline Hy6 & $.453^{* *}$ & $.463^{* *}$ & $.383^{* *}$ & $.713^{* *}$ & $.701^{* *}$ & $.728^{* *}$ & $.237^{* * *}$ & $.289^{* *}$ & $.275^{* *}$ & $.345^{* *}$ & $.433^{* *}$ & $.188^{* * *}$ & $.260^{* *}$ & $.691^{* *}$ & 1 & \\
\hline Hy7 & $.414^{* *}$ & $.407^{* *}$ & $.382^{* *}$ & $.648^{* *}$ & $.677^{* *}$ & $.606^{* *}$ & $.269^{* * *}$ & $.317^{* * *}$ & $.322^{* *}$ & $.489^{* *}$ & $.506^{* *}$ & $.302^{* *}$ & $.357^{* *}$ & $.595^{* *}$ & $.711^{* *}$ & 1 \\
\hline Mean & 7.39 & 7.40 & 8.17 & 8.51 & 8.51 & 8.92 & 3.44 & 4.31 & 3.82 & 4.95 & 2.03 & 4.30 & 4.13 & 5.44 & 5.73 & 2.45 \\
\hline S.D. & 2.63 & 2.70 & 2.38 & 2.66 & 2.58 & 2.55 & 1.63 & 1.70 & 1.94 & 2.19 & 1.09 & 1.83 & 2.09 & 1.90 & 1.77 & .98 \\
\hline
\end{tabular}

\section{Confirmatory Factor Analysis}

Examination of the measurement model showed a satisfactory fit: $\chi^{2}=230.93$ (93), $p$ $<.001 ; \mathrm{CFI}=.953 ; \mathrm{TLI}=.943 ; \mathrm{RMSEA}=.076(90 \% \mathrm{CI}=.063-.088)$. The next part of the analysis was to discern the extent to which the measurement model was invariant across disability groups. A series of progressive steps outlined by Bentler (1995) were followed. SEM multisample analysis begins by establishing a good-fitting model separately for the different groups. Acceptable-fitting model emerged for normal, LD, and ID groups: $\chi^{2}(94)=131.237$ (normal)/179.23 (LD)/168.128 (ID), $p<.001 ;$ CFI = .930/.926/.900; TLI = .910/.906/.872; RMSEA = .089/.098/.086for normal, LD and ID, respectively. 


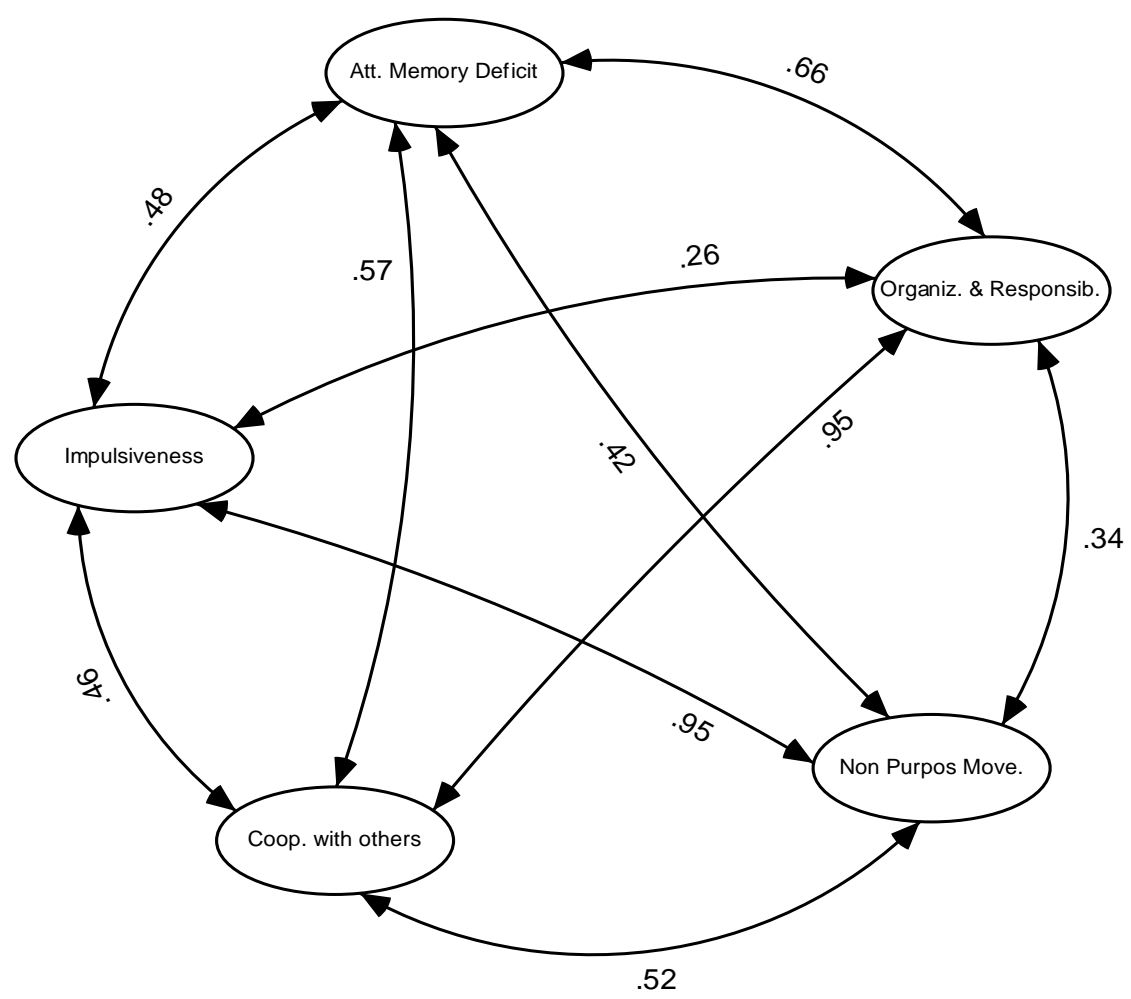

Figure1. Correlations among the factors of the OSADHI from CFA.

Modification indices - as provided by AMOS 16- indicated that the model for the ID can be significantly improved if four of the parcel residuals were free to correlate. Two correlation estimates were freed and the fit was acceptable with $\chi^{2}(92)=144.7, \mathrm{CFI}=.929, \mathrm{TLI}=$ .907, RMSEA $=.073(90 \% \mathrm{CI}=.049-.095)$. Statistics like the GFI are known to be biased and less accurate for testing model fit than the CFI and TLI. GFI was .893 while AGFI = .845. Given that no further logical revisions were warranted, the next step was to run an unconstrained model simultaneously for the three groups. This step serves as a baseline for testing the equality of parameter constraints in subsequently increasingly restrictive nested models.

The fit of the baseline model was a little poor $\left(\chi^{2}=665.499(343), p<.001\right.$; CFI $=$ .867 ; TLI $=.860 ;$ RMSEA $=.061)$, a model constraining the equality of factor loadings across groups was tested and produced a poorer fitting model than the unconstrained with equal fit indices. The equality of the covariances of the latent factors were the next set of constraints imposed and the results revealed a less satisfactory model fit, $\chi^{2}=695.665$ (365) CFI $=.864$; $\mathrm{TLI}=.866 ;$ RMSEA $=.060$. Therefore the model can't be considered invariant across the 
three groups (normal, LD, and ID). Accordingly, we chose to test invariance across two groups rather than three: invariance across normal and LD; and invariance across LD and ID. Since normal students and LD students are in the same school it is reasonable to test the invariance across these two groups. The fit of the model was accepted with $\chi^{2}=383.54$, DF $=$ $227, \mathrm{CFI}=.907, \mathrm{TLI}=.902, \mathrm{RMSEA}=.072 . \mathrm{LD}$ and $\mathrm{ID} \chi^{2} 2=429.02, \mathrm{DF}=227, \mathrm{CFI}=.893$, $\mathrm{TLI}=.887, \mathrm{RMSEA}=.065$. The model of invariance across LD and ID was better than when the three groups were considered, but still the fit was poor.

The effect of disability type and gender. MANOVA with disability type (normal, L.D., and I.D.) and gender as the independent variables and the five subscale scores as the dependent variables was conducted. MANOVA results showed an overall main effect of type $\left(\right.$ Lambda $\left.=.479 ; \mathrm{F}_{(10,490)}=21.78, p<.0001\right)$ and gender $\left(\operatorname{Lambda}=.945 ; \mathrm{F}_{(5,245)}=2.84, p<.02\right)$. Univariate analyses revealed a main effect of disability type for attention and memory deficit $\left(\mathrm{F}_{(2,249)}=49.98, p<.0001\right)$; for organization and responsibility $\left(\mathrm{F}_{(2,249)}=98.57, p<.0001\right)$; for non-purposive movement $\left(\mathrm{F}_{(2,249)}=6.24, p<.01\right)$; for cooperation with others $\left(\mathrm{F}_{(2,249)}=66.0, p<\right.$ $.0001)$, and for impulsiveness $\left(\mathrm{F}_{(2,249)}=8.63, p<.0001\right)$.

Table 3. Means and standard deviations from the MANOVA and multiple comparisons with Scheffe.

\begin{tabular}{lccc}
\hline \multicolumn{1}{c}{ Dependent Variables } & Normal $(\mathrm{N}=51)$ & L.D. $(\mathrm{N}=96)$ & I.D. $(\mathrm{N}=108)$ \\
\hline Attention \& Memory Deficit & $15.65(4.39)_{\mathrm{a}}$ & $24.30(6.38)_{\mathrm{b}}$ & $25.23(5.91)_{\mathrm{b}}$ \\
Organization \& Responsibility & $16.02(5.75)_{\mathrm{a}}$ & $26.72(5.47)_{\mathrm{b}}$ & $28.68(5.03)_{\mathrm{c}}$ \\
Impulsiveness & $10.18(3.72)_{\mathrm{a}}$ & $10.95(4.25)_{\mathrm{a}}$ & $12.77(4.30)_{\mathrm{b}}$ \\
Non-Purposive Movement & $9.47(4.09)_{\mathrm{a}}$ & $11.18(4.88)$ & $12.22(4.25)_{\mathrm{b}}$ \\
Cooperation with Others & $9.04(3.30)_{\mathrm{a}}$ & $13.81(3.58)_{\mathrm{b}}$ & $15.62(3.12)_{\mathrm{c}}$ \\
\hline
\end{tabular}

Note. Different subscripts denote means that means are significantly different within each row.

Table 3 shows the multiple comparisons with Scheffe tests $(p<.05)$. Table 3 revealed that intellectually disabled (ID) children ( $M=25.23, \mathrm{SD}=5.91)$ scored significantly higher than normal children $(\mathrm{M}=15.65, \mathrm{SD}=4.39)$ but not significantly different from the learning disability $(\mathrm{LD})$ children $(\mathrm{M}=24.30, \mathrm{SD}=6.38)$. Also ID children $(\mathrm{M}=28.68, \mathrm{SD}=5.03)$ scored significantly higher than $\mathrm{LD}(\mathrm{M}=26.72, \mathrm{SD}=5.47)$ and than normal children $(\mathrm{M}=16.02, \mathrm{SD}=5.75)$ on the organization and responsibility subscale. The ID $(\mathrm{M}=12.22, \mathrm{SD}=4.25)$ scored signifi- 
cantly higher than the normal children $(\mathrm{M}=9.47, \mathrm{SD}=4.09)$ but not significantly different from $\mathrm{LD}$. The ID (M=15.62, $\mathrm{SD}=3.12)$ scored significantly higher than the normal children $(\mathrm{M}=9.04, \mathrm{SD}=3.30)$ and higher than $\mathrm{LD}(\mathrm{M}=13.81, \mathrm{SD}=3.58)$. Also, LD children scored significantly higher than normal children. Unexpectedly, however, ninth graders $(M=29.76$, $\mathrm{df}=7.38)$ scored significantly higher than eighth graders $(\mathrm{M}=27.25)$,

\section{Discussion}

In this study we set out to examine the discriminant and construct validity of the Omani Scale of Attention Deficit-Hyperactivity and Impulsivity (OSADHI). We were interested in examining the pattern of relations among the five factors and possible differences in the pattern due to disability type. The results of SEM indicated that the model with five different but correlated factors had a good fit. However, when the model was examined for equality across groups, the fit was found to be poor. When only two groups (normal, LD and ID) were included, the analysis produced acceptable fit. This can be explained by the fact that normal and LD children were in the same school; and were assessed by the same raters. Therefore, the structure of the attention deficit-hyperactivity and impulsivity is similar across the two groups and any variance can be conceived of as a form of individual and group differences and not a difference in the structure.

This is probably true, if we know that the diagnosis of the LD children is based on inaccurate tools. For example, the teachers in those schools indicated that they mainly rely on school marks in mathematics and reading, but rarely rely on intelligence tests. Even when intelligence tests are used, standards are not those derived from local populations, which may cause diagnosis to be an invalid one.

The structure of the instrument was invariant when LD and ID children were considered. This may imply that the setting in which each group was enrolled did not affect the rating and the structure of the underlying factors. That is, LD and ID students were not in the same schools. LD students were in regular schools while ID children were in special education institutions. However, the limitation that relates to diagnosis still holds for ID children too. Although the ID is more evident and easily observed, the diagnosis in most of the institutions is mainly based on observed characteristics or intelligence tests with foreign and obsolete standards. In some cases, diagnosis is based on school performance. 
It can be concluded that the underlying factors of the ADHD are more than three as was established in previous research. Rather, the phenomenon is a multifaceted one. The results of this study revealed that five dimensions underlie the various behaviors of the ADHD children. The implication of this result is that diagnosis as well as treatment should be directed towards attention and memory; organization and responsibility; non purposive movement; cooperation with others; and impulsiveness rather than only three dimensions (i.e., attention deficit, hyperactivity and impulsiveness).No previous research was conducted in the Arab Worled was conducted and provided support for the present study. In Fact, the present stuy is probable the first in teh Arab World. Therefore, no conclusive evidence can be obtained to support the heypotheses related to the present stydy until further studies are conducted.

Effect of disability type. MANOVA revealed that the three groups (normal, LD, ID) significantly differed on all of the five subscales. The univariate analysis and the multiple comparisons with Scheffe test indicated that the three groups were significantly different on all five subscales. Specifically, normal children significantly scored lower than LD and ID children on AMD, but no significant difference occurred between LD and ID children. Previous research has confirmed that AMD is one of the main characteristics of LD and ID children (American Psychiatry Association, 2000; Deutsch, Dube, \& McIlvane, 2008; Seager \& O'Brien, 2003) and not one of the normal children characteristics. This result provides support to the findings of Karande and colleagues (2007) that LD children suffer from inattention and daydreaming. Also, attention and memory are closely related to academic performance. Since diagnosis rely heavily on academic performance (e.g., mathematics and reading) that requires attention and memory, raters seemed to have differentiated between normal and $\mathrm{ID}$ children. ID children are known to suffer from problems with attention and memory (Deutsch et al., 2008).

In regard to OR, the three groups differed significantly. The normal children were more organized and responsible than LD and ID children. Also, LD children were rated higher than ID children on the same subscale. This result is not surprising since lack of organization and dependence on the others are traits of LD and ID children.

As for IM, normal and LD children were less impulsive than ID children. Failgel (1998) found that most ADHD children may have learning difficulty but less than $25 \%$ of LD children may have ADHD. With the limitations in the diagnosis in Oman, it seems reasonable to 
conclude that impulsiveness is a trait of ID children but not necessarily a trait of LD children who we don't know for sure that they are LD's.

As for NPM, as part of hyperactivity, the difference occurred between normal and ID children only. Again the non purposive movement is not a characteristic of normal or LD children but a characteristic of ID children (Deutsch et al., 2008; Failgel, 1998).

Finally, the result of the $\mathrm{CO}$ repeats the pattern of differences in the OR results. The three groups differed significantly on this subscale. It is evident that both $\mathrm{CO}$ and OR have a social component. CO and OR are the only subscales where the three groups differed.

The social component entails that the assessed behaviors are learned from the surrounding environment and from interaction with others. However, since LD children are sometimes stigmatized, they may react to such stigmatization and may fail to develop socially acceptable behaviors. In comparison, AMD, in particular, is not something that children can learn or imitate, but it is a cognitive attribute that an individual may or may not have. Hence, the difference was not clear between LD and ID children.

On the other hand, however, the three groups were clearly different from one another on the constructs with social components. The implication of this is that LD children may be able to learn these social behaviors if suitable treatment and environment are provided.

In conclusion, this study revealed that the Omani Scale of Attention Deficit Hyperactivity Impulsiveness possesses good reliability and validity estimates and can be used as a diagnostic and research tool with LD, ID and normal children. The instrument added to our knowledge of the nature of the attention deficit hyperactivity phenomenon in that two of the main components of the instrument reflected both developmental and psycho-social or may be called behavioral. The two components are attention deficit and hyperactivity. Further research is needed in the future to validate the structure of the instrument with larger and varied samples. 


\section{References}

Abu-Hilal, M., \& Bahri, T. (2000). Self-concept: the generalizability of research on the SDQ, Marsh/Shavelson model and i/e frame of reference model to United Arab Emirates students. Social Behavior and Personality, 28, 309-322.

Adler, L., Spencer, T., Faraome, S., Kessler, R., Howes, M., Biederman, J., \& Secnik, k. (2006). Validity Pilot adult ADHD self report (ASRS) to rate adult ADHD symptoms Annals Clinical Psychiatry, 18 (3), 145-148.

Aldhaher, Q. (2004). Learning disability. Amman: Dar Alfeker.

Alhamed, H. (2002). ADHD Causes and treatments. SA: Arabian academy for special education publisher.

Alkhatib, J., \& Alhadidi, M. (2004). Training program for mental retardation. Amman: Dar Alfeker.

Alkwafha, T. (2005). Learning disability and the remedial plan. Amman :Dar Almasira for publishing.

Alqabali, Y. (2005). Introduction to learning disability. Amman: Altariq for publishing.

Alrusan, F. (2006). Tthe intelligence and the adapted behavior. Amman: Dar Alfeker.

Alsayed, A. (1999). Attention deficit disorder and hyperactivity child scale. Egypt:Alnahdhah Egyptian library.

Alsayed, A., \& Bader, F. (2004). Attention deficit disorder and hyperactivity child.SA:The Arabian academy for special education for publishing.

Alwaqfi, R. (2003). Learning disability. Amman: Princes Tharwat college publication.

Alzayat, F. (1998). Learning disability. Egypt: Dar Alnasher.

American Psychiatry Association (APA). (2000). Diagnostic and statistical manual of mental disorder. DSM-IV-TR ( $4^{\text {th }}$ Ed) Washington DC: Author.

Barkly, R. (1998). Attention deficit hyperactivity disorders. A handbook for diagnosis and treatment. (2ed Ed) New York: the Clifford press.

Bentler, P. (1995). EQS: Structural equations program manual. Encino, CA, Multivariate Software Inc.

Conner, C. (1997). Conner's rating scales. North Tona Wanda NY: Mult heath systems.

Deutsch, K., Dube, V., \& McIlvane, J. (2008). Attention deficit, attention-deficit hyperactivity disorder, and intellectual disabilities. Developmental Disabilities Research Reviews, $14,285-292$. 
Dills, R. (2003). Diagnosis and treatment of attention deficit hyperactivity disorder. Pharmacy Times, 69,9,66.

Eiraldi, T., Power, T., \& karustis, J . (2000) Assessing ADHD and co morbid disorders in children: the child behavior checklist and the Devereux scales of mental disorders. Journal Child Psychology, 29 (1), 3-16.

Failgel, H. (1998). Learning disabling or attention deficit disorder: which is It.? Learning Disability Journal, 8 (2), 5-8.

Hallahan, D., \& Kauffman, J. (2003). Exceptional children: introduction to special education. $\left(4^{\text {th }}\right.$ Ed) New Jersey: Engle wood Cliffs.

Hallahan, D., Lloyed, J., Kauffman, J., Weiss, M., \& Martinez, E. (2005). Learning disabilities: foundations, characteristics, and effective teaching. New York: Pearson Education, Inc.

Jarrar, A. (2008). Learning disability. UAE: Alfalah Publisher.

Jou, R., Handen, B., \& Hardan, A. (2004). Psycho stimulant treatment of adults with mental retardation and attention deficit hyperactivity disorder. Australian Psychiatry. 12 (4), 376-379.

Jreisat, R. (2007). Constructing a scale for diagnosing attention deficit hyperactivity disorder and ascertaining its efficacy for normal, learning disabled, mentally retarded, and autism students. Unpublished dissertation, Amman Arab University for higher studies, Jordan.

Karande, S., Satan, N., kulkanri, M., sholapurwala, P., Chitre, A., \& Shah, N. (2007). Clinical and psycho educational profile of children with specific learning disability and cooccurring attention-deficit hyperactivity disorder. Indian Journal Med-Sci, 61 (12), 639647.

Lerner, J. (2003). Learning disabilities: theories, diagnosis and teaching Strategies. $\left(9^{\text {th }} \mathrm{Ed}\right)$ Boston: Houghton Mifflin Company.

Lahey, B., Pelham, W., Chronis, A., Massetti, G., Kipp, H., Ehrhardt, A., \& Lee, S. (2006). Predictive validity of ICD-10 hyperkinetic disorder relative to DSM-IV attention deficit, hyperactivity disorder among younger children. Journal of Child Psychology and Psychiatry, 47 (5), 472-474.

Marsh, H., Byrne, M., \& Shavelson, J. (1988). A multifaceted academic self-concept: Its hierarchical structure and its relation to academic achievement. Journal of Educational Psychology, 80, 366-380.

Mercer, C. (1997). Student with learning disability. (5th) New Jersey: practice Hale.

Salehi, S., Noah, S., \& Jaafar, W. (2011, May). Primary school teachers perceptions about attention deficit and sense of time among ADHD children. Paper presented at the $4^{\text {th }}$ International Conference of Cognitive Science. Tehran, Iran. 
Salem, M., Alshahat, M., \& Ashoor, A. (2003). Learning disability. Amman: DarAlfeker.

Seager, M., \& O'Brien, G. (2003). Attention deficit hyperactivity disorder: review of ADHD in learning disability: the diagnostic criteria for psychiatric disorders for use with adults with learning disability / mental retardation [Dc-LD] criteria for diagnosis. Journal of Intellectual Disability Research. 47 (1), 26-31.

Shaban, S., Mohamed, O., \&Jaafar, W. (2011, May). Elementary school students with ADHD: Two perceptions toward problem solving. Paper presented at the $4^{\text {th }}$ International Conference of Cognitive Science. Tehran, Iran.

Simonsen, B., \& Bullis, M. (2007). The effectiveness of using a multiple gating approach to discriminate among ADHD-subtypes. Journal of Emotional and Behavioral Disorders, 15 (4), 223-336.

Sisalem, K. (2001). ADHD Characteristic, causes and treatment. UAE: University book house.

Smith, k., \& Corkum, P. (2007). Systematic review of measures used to diagnose attention-deficit, hyperactivity disorder in research on preschool children. TECS, 27(3), 164-173.

Word Health Organization. Mental and behavior disorders. \{On line\} http://wwwwho.int/classification/apps/lcd/lcd15,?qfgo.htmtfgo.

Yehia, K., \& Obied, M. (2005). Mental retardation. Amman: Dar Wael. 


\section{Appendix}

The Items of the Omani Scale for Attention Deficit Hyperactivity and Impulsivness (OSADHI)

\begin{tabular}{|c|c|}
\hline Ser. & Item \\
\hline 1. & S/he suffers from absent-mindedness and daydreaming. \\
\hline 2. & S/he forgets important things in performing tasks. \\
\hline 3. & S/he performs tasks entrusted to him/her. \\
\hline 4. & S/he fails to follow given instructions. \\
\hline 5. & S/he avoids tasks that require mental effort and concentration. \\
\hline 6. & S/he suffers from confusion and bewilderment. \\
\hline 7. & S/he fails to complete activities that he/she starts. \\
\hline 8. & S/he maintains his/her books and stationary in order. \\
\hline 9. & $\mathrm{~S} /$ he forgets the information that $\mathrm{s} / \mathrm{he}$ learns. \\
\hline 10. & $\mathrm{~S} / \mathrm{he}$ is persistent. \\
\hline 11. & $\mathrm{~S} / \mathrm{he}$ listens to what is said to him/her \\
\hline 12. & S/he gets distracted in noisy places. \\
\hline 13. & S/he remembers appointments (e.g., exams, picnics, etc.). \\
\hline 14. & S/he understands the questions addressed to him/her. \\
\hline 15. & S/he pays attention to time. \\
\hline 16. & $\mathrm{~S} / \mathrm{he}$ is independent in doing his/her work. \\
\hline 17. & $\mathrm{~S} / \mathrm{he}$ is often bored and restless and frequently moves around. \\
\hline 18. & S/he makes noise in class. \\
\hline 19. & S/he disturbs other students and is not on good terms with them. \\
\hline 20. & S/he co-operates with teachers and supervisors. \\
\hline 21. & S/he apologizes if s/he behaves inappropriately. \\
\hline 22. & S/he frequently and aimlessly stands up and sits down in class. \\
\hline 23. & $\mathrm{~S} / \mathrm{he}$ runs jumps and climbs on furniture. \\
\hline 24. & S/he asks for permission when he/she takes toys of other children. \\
\hline 25. & S/he cares about his personal cleanliness. \\
\hline 26. & $\mathrm{~S} / \mathrm{he}$ is messy (doesn't return things to their proper places). \\
\hline 27. & S/he crashes and collides with the furniture when moving around. \\
\hline 28. & $\mathrm{~S} /$ he positively responds to the teacher's instructions. \\
\hline 29. & S/he moody. \\
\hline 30. & S/he likes to see that his demands are answered promptly. \\
\hline 31. & S/he screams and cries a lot. \\
\hline 32. & S/he likes to fight with his peers. \\
\hline 33. & S/he runs and jumps quickly with no consideration of consequences. \\
\hline 34. & $\begin{array}{l}\text { S/he sticks his/her nose in dangerous activities without thinking about } \\
\text { results. }\end{array}$ \\
\hline 35. & S/he faces difficulty in planning and organization. \\
\hline 36. & S/he finishes tasks in due time. \\
\hline
\end{tabular}

